\title{
The Correlates and Treatment of Obesity in Military Populations: A Systematic Review
}

\author{
Paul W. Sanderson Stacy A. Clemes Stuart J.H. Biddle \\ School of Sport, Exercise and Health Sciences, Loughborough University, UK
}

\section{Keywords}

Systematic review - Obesity - Military population . Correlates · Treatment

\section{Summary \\ Objective: The emergence of obesity as a distinct disease could have far reaching consequences for an organisa- tion where optimum health and physical fitness are required for personnel to perform their occupational roles effectively. The objectives of this paper are to systematically review the literature concerning corre- lates and treatment of obesity in military populations. Methods: Through computerised searches of English language studies, 17 papers were identified (treatment (13), correlates (4)). Results: Successful treatment inter- ventions incorporated exercise, healthy eating informa- tion, behavioural modification, self-monitoring, relapse prevention, and structured follow-up and were sup- ported by trained personnel. Efficacy due to physical activity was underreported. Reduction in body fat rather than body weight was the most significant outcome. The major significant correlates of obesity were being enlisted personnel, male, $\geq 35$ years of age, African-American/ Hispanic ethnicity, and married (with spouse present). Conclusion: This systematic review highlights the deficit in knowledge concerning treatment and the lack of engagement in relation to the specific correlates of obesity in military populations.}

\section{Introduction}

With the global epidemic of obesity [1], some nations have identified a trend towards escalating levels of overweight and obesity within their military populations [2, 3]. It would appear that, despite body fat standards being imposed on military personnel, the armed forces population are experiencing similar patterns of increasing levels of overweight and obesity as observed in civilian society [3,4]. A recent study from the US Department of Defence (DoD) $(n=16,146)$ indicates that $61 \%$ of men and $39 \%$ of women employed in the active component of the US Military are overweight and collectively $12 \%$ are obese [3]. Evidence from the UK shows lower collective values with $38 \%$ being overweight and $14 \%$ obese $(n=4,500)$ [5], but still being suggestive of a problem.

Several studies have investigated the associated costs of obesity to the military [6-8]. Dall and colleagues [6], for example, estimated that the financial cost of excess weight and obesity to the DoD was USD 1.1 billion. Such findings were corroborated by data from the US Medical Surveillance Monthly Report for January 2009 [3], indicating that 23\% and $16 \%$ of US Service members diagnosed with overweight or obesity in 2008 had at least one medical encounter for a joint and back pain disorder, and that these conditions were among the leading causes of health care costs and lost duty time. Whilst the financial connotations of obesity are clearly important, the psychological and physiological impact to service personnel may have wider occupational implications due to the association between obesity and depressive symptoms [9], post-traumatic stress syndrome (PTSD) [10], cardiorespiratory fitness (CRF) and neuromuscular fitness [11], heat stress [12], sleep apnoea [13], and load carriage [14, 15]. Several investigations into load carriage within military populations have observed that 'load carriage' ability was reduced in 'over-fat' military personnel [14, 15]. Fogelholm et al. [11], concluded that individuals with higher levels of body fat had

\section{KARGER \\ Fax +497614520714 \\ Information@Karger.de}

www.karger.com (c) 2011 S. Karger GmbH, Freiburg

$1662-4025 / 11 / 0043-0229 \$ 38.00 / 0$

Accessible online at:

www.karger.com/ofa
Paul W. Sanderson

Centre for Global Health and Human Development

School of Sport, Exercise and Health Sciences, Loughborough University

Ashby Road, Loughborough, Leicestershire LE11 3TU, UK

P.W.Sanderson@1boro.ac.uk 
not only impaired CRF but also reduced muscular and motor function, reducing the over-fat individual's ability to complete physically challenging military tasks.

Studies attempting to explore trends between physical activity (PA) and overweight [16], and the correlates of obesity [17], have to date been conducted on the general population and may not reflect a sub-population with relatively high levels of PA, such as the military [18]. Therefore, a greater understanding of the correlates of obesity could offer a means to mediate the effect on the military, allowing for specific prevention and treatment interventions. Given the established links between obesity and the major causes of morbidity and mortality [19] and their impact on personal and collective 'operational effectiveness' [20], the aim of this paper was to systematically review the current evidence in respect of the correlates and treatment of obesity in the armed forces.

\section{Material and Methods}

This study followed the procedures for systematic reviews outlined by the National Health Service (NHS) Centre for Reviews and Dissemination [21], and the National Institute for Health and Clinical Excellence (NICE) 'Methods for the Development of NICE Public Health Guidance' [22].

\section{Search Strategy}

The following electronic databases were searched, CINAHL, MedLine (PubMed), OCLC First Search, CSA Illumina, Sports Discus, and Cochrane electronic databases using the search terms 'Military' or 'Army' or 'Air Force' or 'Navy' or 'Marines' AND 'weight', 'overweight', 'obesity', 'weight maintenance', 'weight loss' or 'weight control'. Due to the restricted nature of some material concerning the military, an additional search of all military sponsored literature was conducted. This search strategy included numerous e-mails to several world-wide military departments (DoD, Australian Defence Force, New Zealand Army and Canadian Army etc.) and a focussed search of the North Atlantic Treaty Organisation (NATO) medical research publications.

\section{Inclusion and Exclusion Criteria / Identification of Relevant Studies}

For inclusion, studies were required to i) refer to a regular (as opposed to reservist) military population, ii) have an outcome that was weight-, health- or PA-related, and iii) be written in the English language and published between 1990 to May 2009. Studies were excluded if i) the focus was surgical or pharmaceutical, or ii) the intervention did not include obesity as a primary condition. The first author identified relevant papers through the search strategy by reading their titles and abstracts. If abstracts were not available or yielded insufficient data, the whole article was screened for suitability for inclusion. Data from papers meeting the inclusion criteria were extracted by the first author on a standardised form developed for this review

Study Type and Quality Appraisal

Studies were categorised by study design as described in the NICE 'Methods for Development of NICE Public Health Guidance' Annex D and E [22]. Quality appraisal was reflective of:

- Population: source, recruitment and representation

- Method of allocation: randomization, concealment and exposure

- Outcomes: measurement, reliability and follow-up

- Analyses: methods, intention to treat and calculable effect sizes

- Summary: validity and generalisability of findings.

\section{Results}

The literature searches yielded 595 potentially relevant articles. Based on the title and abstract, 544 papers were removed from the review. Duplications accounted for 2 papers; a further 29 papers did not withstand the criteria for the review (fig. 1). A final confirmatory filter with a second reviewer (SJHB) reduced the remaining 20 papers to 17 . Of the papers included in the review, only one paper was from outside the USA (Israel). The 'grey literature' search returned 18 potential papers, none of which could be included in the review. In the main, these papers focussed on 'military policy' regarding obesity classification and associated regulations (fig. 1).

Papers were filtered into the sub-categories of treatment $(\mathrm{n}=13)$ and correlates $(\mathrm{n}=4)$. The quality appraisal by subcategory is shown in table 1. A quality assessment of '++' was allocated to the two randomized controlled trials (RCTs) and the one cluster randomized controlled trial (CRCT); the non-randomized controlled trial (NRCT) was assessed as ' + '. The remaining papers were cross-sectional $(\mathrm{CS})(\mathrm{n}=4)$ and non-experimental pre-post (NEPP) $(\mathrm{n}=9)$, and were assessed as '-'.

\section{Treatment}

13 studies $(\mathrm{RCT}=2, \mathrm{CRCT}=1, \mathrm{NRCT}=1, \mathrm{NEPP}=9)$ examining the treatment of obesity in military populations were reviewed (table 2). The period of intervention ranged from 3 weeks to 12 months, with an associated follow-up of 3-18 months. The average sample size was 134 (range 31-624), and the reported average age was 31.5 years (range 19-50 years). In general terms the sampling reflected both genders $(n=10)$; however, 3 studies reflected a single sex sample ( 2 male, 1 female). The majority of papers $(n=9)$ reported an intervention based on cognitive behavioural theory (CBT; $n=8)$, or the transtheoretical model (TTM; $\mathrm{n}=1)$. All interventions included PA as part of the treatment process; diet modification was offered by 9 of the interventions [23-31], with diet education incorporated into all but one [32]. With the exception of 3 interventions [26, 32, 33], self-monitoring techniques were generally included. Behavioural or lifestyle change was a central topic in all but one of the interventions [32], whilst creating a supportive environment was only partially referred to in 8 of the interventions [23-30], each of which followed a 'cognitive-behavioural' approach. Significantly the intervention that used PA in isolation [32] was the least effective, achieving $<1 \%$ weight loss. Where comparison is possible $[34,35,54]$, a reduction in reported body fat (Cohen's $d=$ $0.42-0.66)$ as opposed to body weight $(d=0.14-0.38)$ or BMI ( $d=0.03-0.53)$ was observed to be more significant. Several of the interventions [26-30,34] could be defined as successful as they produced reductions in body weight beyond that required by the US Institute of Medicine [35] ( $\geq 5 \%$ of initial body weight). Whilst the most successful (>10\% weight loss) interventions [29, 30] all followed the 'Healthy Lifestyles, Ex- 


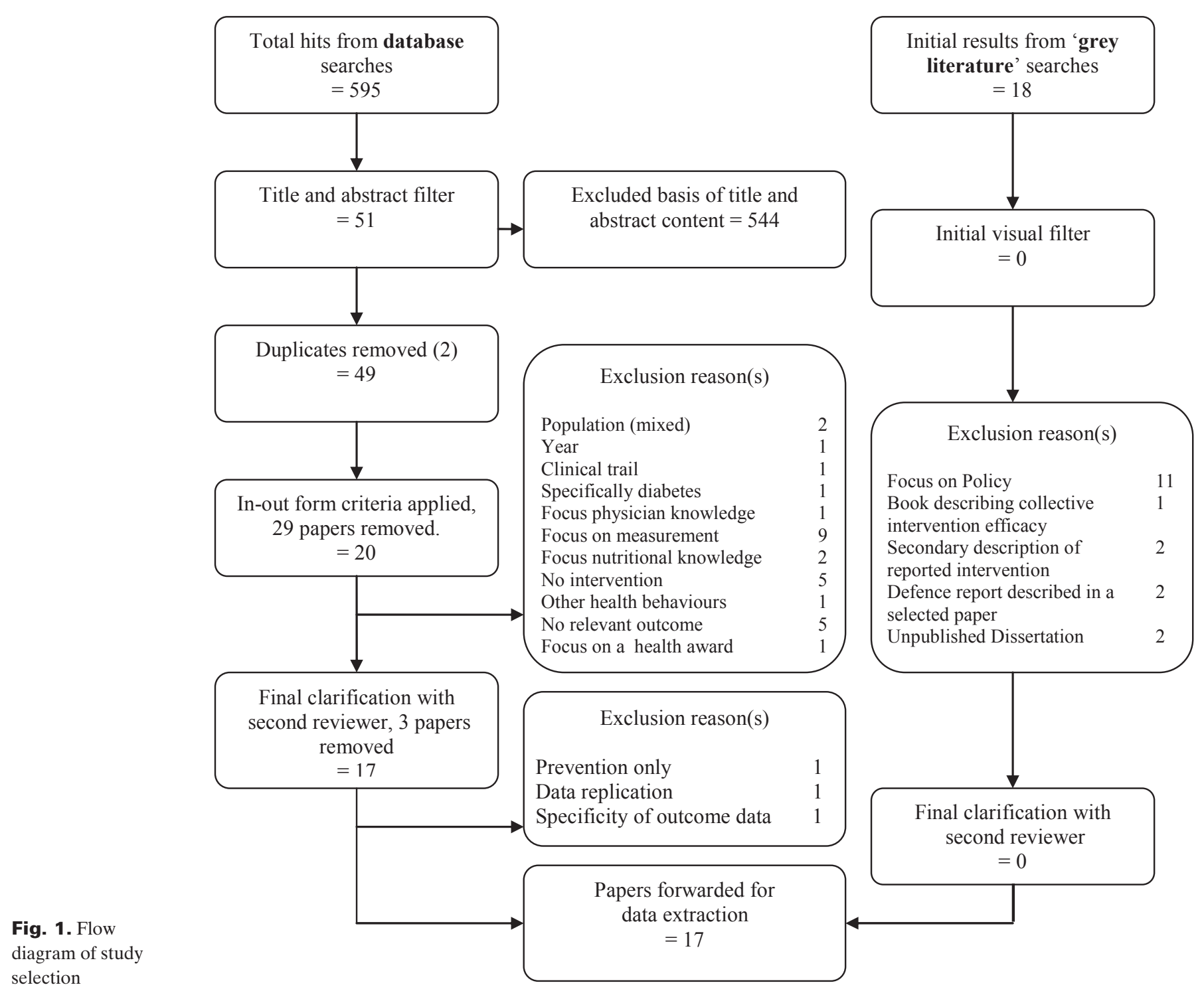

Table 1. Quality assessment by sub-category

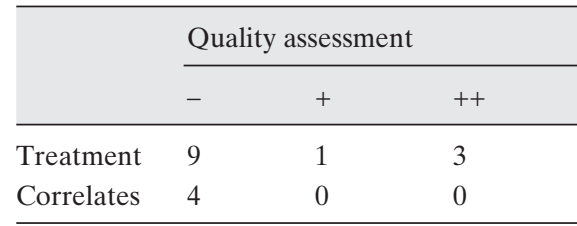

ercise and Emotions, Attitudes and Nutrition' (LEAN) programme, these interventions reflected individuals that were heaviest at baseline in comparison with the participants taking part in the other studies reviewed.

\section{Correlates}

Four cross-sectional studies concerning the correlates of obesity were included in this review. Table 3 follows a similar approach advocated by previous reviews $[17,36,37]$ and classifies correlates as demographic and biological; psychological, cognitive and emotional; dealing with behavioural attributes and skills; social and cultural; dealing with physical environment; or dealing with PA characteristics. The study populations ranged from 27 to 46,213 and reflected both genders $($ male $=78 \%(\mathrm{n}=36,021) ;$ female $=22 \%(\mathrm{n}=10,192)) ;$ age ranged between 18 and 55 years. A total of 19 correlates were identified from the 4 papers, with all of the evidence being based on 1 of the studies, or on 2 studies with conflicting evidence; therefore the quality of the evidence is classified as weak or mixed. These 19 correlates consisted of 8 demographic and behavioural, 5 psychological, cognitive and emotional, and 3 environment factors. One correlate was identified for behavioural attributes and skill. Social and cultural 


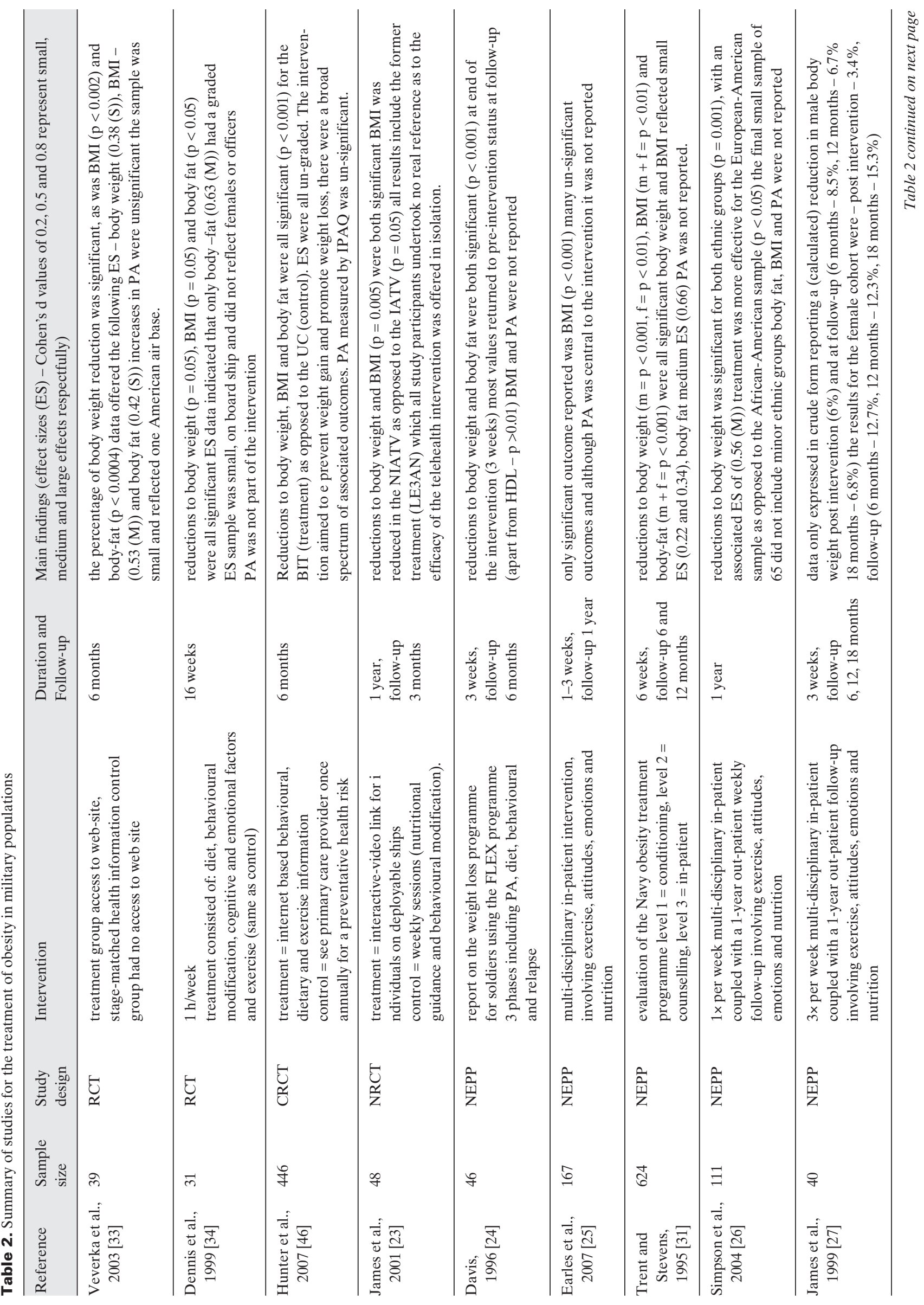




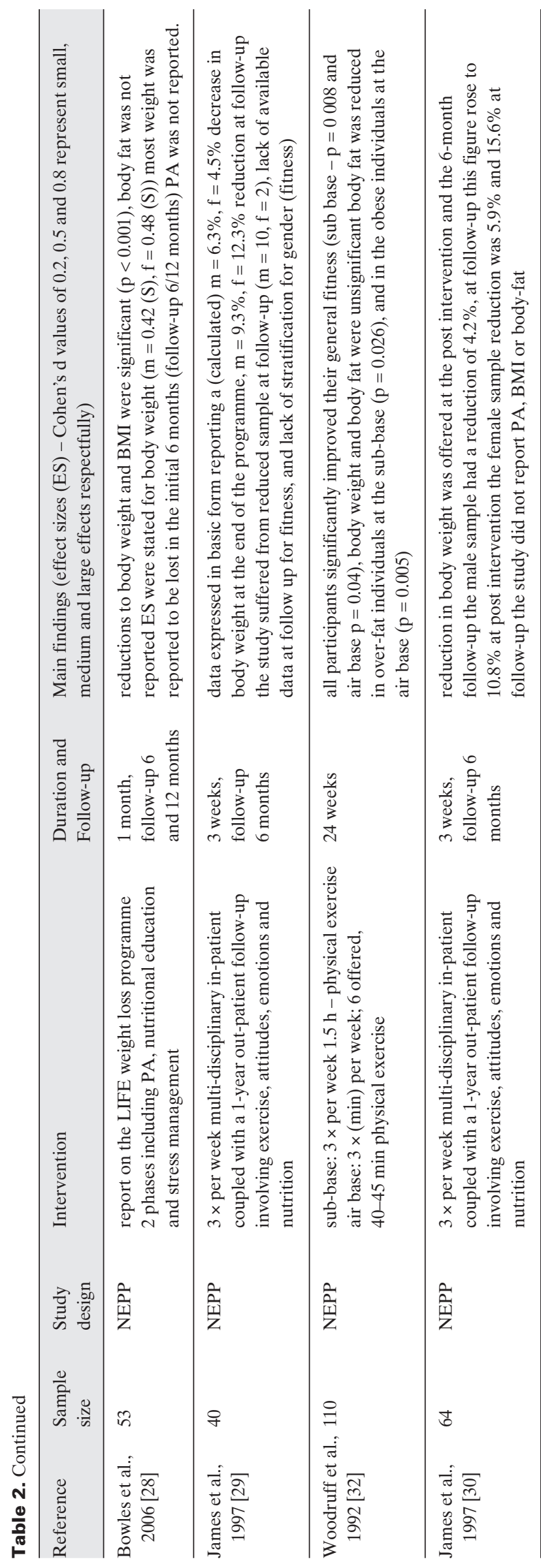

factors were represented by a single correlate, as was PA characteristics. The information offered by Bray et al. [20] represents the strongest evidence as data is derived from large-scale probability samples from three separate surveys (1995, 1998 and 2002). This study concluded that age, education, gender, pay group, marital status, and ethnicity were all significant $(\mathrm{p}<0.05)$ correlates of obesity. Based on a large mixed Israeli sample $(n=22,671)$, Grotto et al. [38] reported that education (both participant and parents), smoking status, and PA level were linked to obesity status ( $\mathrm{p} \leq 0.035)$. Sigrist et al. [39] focussed on a small sample of senior officers $(n=52)$; the primarily male (93\%) sample indicated that 'not liking cooking' and 'lack of time', and 'low priority' were barriers to eating healthily and undertaking PA. Additionally, this study concluded that 'limited access' to fitness facilities, healthy food choices, and mixed media messages were all factors related to obesity. The final reviewed study [40] concentrated on a small Navy sample $(\mathrm{n}=27)$ and offered one significant correlation $(p<0.05)$ in reference to the 'perceptions of exercise leadership'.

Table 3. Factors associated with becoming overweight/obese

\begin{tabular}{|c|c|c|}
\hline Determinant & Review & Reference \\
\hline \multicolumn{3}{|l|}{ Demographic and biological factors } \\
\hline Age $(\geq 35)$ & + & {$[20]$} \\
\hline Subjects education & 0 & {$[20,38]$} \\
\hline Parents education (father's schooling $\leq 12$ years) & + & [38] \\
\hline Gender (male) & + & {$[20]$} \\
\hline Pay group (enlisted) & + & [20] \\
\hline Marital status (married spouse present) & + & [20] \\
\hline Race/ethnicity (non-white) & + & {$[20]$} \\
\hline Oral contraceptives (females not taking) & + & [38] \\
\hline \multicolumn{3}{|l|}{ Psychological, cognitive and emotional factors } \\
\hline Lack of time (to eat healthily / undertake PA) & + & [39] \\
\hline Low priority (to eat healthily / undertake PA) & + & [39] \\
\hline Do not like to cook & + & [39] \\
\hline Perceptions of exercise leadership & + & [40] \\
\hline \multicolumn{3}{|l|}{ Behavioural attributes and skills } \\
\hline Smoking status (ex smokers) & + & [38] \\
\hline \multicolumn{3}{|l|}{ Social and cultural factors } \\
\hline Armed service (Navy) & + & {$[20]$} \\
\hline \multicolumn{3}{|l|}{ Physical environmental factors } \\
\hline Reduced access to fitness facilities & + & [39] \\
\hline Healthful food choices (not available) & + & [39] \\
\hline Confusion from the media & + & [39] \\
\hline \multicolumn{3}{|l|}{ PA characteristics } \\
\hline PA level (low) & + & [38] \\
\hline
\end{tabular}




\section{Discussion}

The purpose of this systematic review was to evaluate the available literature on the treatment and correlates of obesity in the armed forces. This paper is the first of its kind to systematically review these areas. The main findings of the study will be discussed in terms of these two areas below:

- Treatment

- Correlates.

\section{Treatment}

Of the 13 reported studies, $6[23,25-27,29,30]$ referred to the LEAN intervention programme. However, each study reported on either a specific population or an evolution of the original framework based on CBT. A similar 'cognitive behavioural' approach was also followed in the 'Lifestyle Change, Individual Readiness, Fitness Excellence and Eating Healthy' (LIFE) [28] and 'Fat Loss and Exercise' (FLEX) [24] programmes. The TTM was applied in 1 study [33], with the remaining 4 studies having no reported theoretical framework. Universally the interventions that were supported by theoretical methodologies displayed greater efficacy in respect of weight loss. Previous reviews have highlighted the value of using behavioural theory to clarify individual component effectiveness [19] and the influence of mediating variables [41].

Most interventions incorporating PA were poorly described, with little reference made to the prescriptive elements. All LEAN intervention programmes [23, 25-27, 29, 30] advocated low intensity PA (a target pulse rate of $60-70 \%$ of maximum heart rate) for $40 \mathrm{~min}$ (Monday to Friday $=200 \mathrm{~min} / \mathrm{week}$ ) [27]. Current recommendations suggest that $45-60 \mathrm{~min} /$ day of moderate intensity activity is required to prevent the transition to overweight or obesity and that $60-90 \mathrm{~min} /$ day is required for the prevention of weight regain in formerly obese individuals [42]. The advocacy of low-intensity PA in the LEAN programmes was based on 1 study using a civilian female sample [43] and may not adequately reflect a sub-population that is predominantly male who regularly engage in vigorous PA. The existence of dietary modification and diet education was another central topic of most of the interventions and is reflective of recent literature $[19,44]$. Two studies $[24,27]$ reported the dietary modification applied (male 1,500-2,000 kcal/day , female 1,400-1,600 kcal/day), and these values are broadly in keeping with civilian recommendations [45]. Whilst both studies were successful in reducing body weight, the 'multi-component' nature of the interventions precludes comment as to the efficacy of the individual component.

With the exception of 5 studies [31-34, 46], general reference was made to the multi-disciplinary nature of the interventions and to the requirement for suitably trained professionals to support the intervention process. Health psychologists, dieticians, physical therapists, and other paraprofession- als supported all of the LEAN programmes [23, 25-27, 29, 30], with similar support evident for the FLEX [24] and LIFE [28] programmes. A self-monitoring process was employed in the majority of interventions. The LEAN programmes incorporated specific self-monitoring techniques, that was based on evidence gained from 'binge eating' [29] which attempted to highlight food relationships (family and social-environmental), and extended beyond food journals utilized in most other interventions [24, 34, 46]. The keeping of detailed records in regards to nutrition and $\mathrm{PA}$ are often considered one of the key features of behavioural therapy [47] and have been associated with quick reductions in food intake and an associated weight loss [48]. Collectively the programmes that employed self-monitoring techniques were the more successful (in terms of $\%$ of body weight lost) than those who did not $[32,33]$.

The most successful interventions [26 ,27, 29, 30] lasted 12 months; however, in the 1 study where data were presented beyond 12 months [29], the majority of weight loss occurred in the first 6 months. These findings were corroborated in an evaluation of the US Navy's obesity treatment programme [31] in that individual weight loss at 6 months remained in a virtual plateau until 12 months. One paper [24] indicated that out-patient follow-up was hampered by changes in assignments, field exercises, and mission requirements. The lack of genuine follow-up in most cases prevents any informed conclusion as to the long-term efficacy of the separate interventions. This fact remains problematic as most weight loss programmes can achieve satisfactory initial weight loss [44]; however, maintenance of weight loss is rarely retained [49].

The majority of the interventions [24, 25, 27-31, 34] delivered the intervention through a combination of group and individual therapy; 4 programmes relied on individual, oneto-one treatment; group therapy alone was utilized by 1 intervention [32]. In general the interventions that used a combined approach were more successful. Two of the interventions that used individual treatment were web-based [33, 46]; both interventions were statistically successful at reducing body weight, BMI, and body fat although the effect sizes were not clinically meaningful for 1 intervention [46]. Internetbased programmes may present a platform for a widespread approach to weight management [50] and offers a possible treatment option for those working in isolated areas. All of the interventions reviewed were undertaken within armed forces real-estate, with all personnel subject to military rules; therefore, attendance may not have been purely voluntary. The LEAN programmes all had a period of in-patient care at an army medical centre. Three other interventions [24, 28, 31] utilized an initial in-patient process for some or all of the tiered interventions. The remaining 4 interventions [32-34, $46]$ were based in the workplace. Of the remaining 2 programmes, 1 [32] compared the efficacy of 2 conditioning programmes for land-based naval personnel. Both programmes utilized exercise as a singular intervention component. Whilst trends towards fitness improvement were reported [32], poor 
compliance and lack of a multi-disciplinary approach were suggested as reasons for the failure to elicit significant changes in weight status. Such findings are supportive of previous studies, suggesting that interventions utilizing a multi-disciplinary approach may be more effective $[44,51]$.

\section{Correlates}

\section{Demographic and Biological Factors}

Bray et al. [20] concluded that a higher educational level was correlated with obesity prevalence in US armed forces personnel. Yet in a study based on the Israeli military [38], lower, but not higher educational level (for study subject and male parent) was correlated to obesity. Current opinion concurs with the findings of Grotto et al. [38] and is supportive of a relationship between lower educational attainment and higher levels of obesity [17]. Bray et al. [20] suggested that 'pay group' status of military personnel was correlated with obesity in that those on lower pay displayed higher levels of obesity. There is a direct correlation between the hierarchical system of rank employed within the military and 'pay-group', with higher rank commanding higher wages. Several studies have highlighted the relationship between socioeconomic status, obesity-relevant health behaviours [52] and income inequality [53]. In one obesity review [54], it was proposed that there may be psychosocial consequences of living in a "more hierarchical society'. Therefore, it is not surprising that obesity was more common in the lower paid 'enlisted ranks' as opposed to the higher paid 'officer class' [20]. Obesity was found to be more prevalent in males aged $\geq 35$ years [20], which has also been observed in civilian samples [17]. Being 'married' was linked to a higher level of obesity [20]. Specifically, married individuals who were accompanied by their wife/partner at their place of work had a higher propensity of obesity. This suggests that future obesity treatment interventions should also include spouses and partners [2]. Within the review stratification the injury status was not alluded to; military populations have high levels of musculoskeletal injury [55], and obesity is one outcome associated with long-term injury [56]. A recent study involving the British Navy [57] stated that those individuals deemed medically unfit $(21.8 \%)$ as opposed to fit $(12.1 \%)$ were almost twice as likely to be obese; therefore, injury status should be investigated further.

\section{Psychological, Cognitive and Emotional Factors}

Lack of time, low priority, and not liking cooking were offered as barriers to healthy living [39], with lack of time and low priority largely attributed as barriers towards PA and healthy eating. Within the correlates of PA, lack of time as a negative association has attracted repeated support $[37,58]$. Although based on a small specific sample, the allocation of time for PA and healthy eating deserves further investigation. Sigrist et al. [39] further concluded that enjoyment of cooking may influ- ence obesity status. Lack of cooking confidence, ability, and enjoyment may impact on the ability to prepare healthy and inexpensive meals [59] and could enforce a reliance on convenience foods, many of which are high in fat [60]. However, this knowledge should reflect the institutional nature of the military services in regards to habitation and access to cooking facilities. The reviewed papers do not attempt to gain an understanding as to the food choices military personnel make or why they participate in PA. Due to the prospective impact of dietary habits and PA, the psychological factors that inform these decisions should be further investigated. Perceptions of exercise leadership displayed a negative association with reductions in body fat. Paradoxically those individuals less approving of the exercise leader displayed greater reductions in body fat [40]. The authors postulated that the greater levels of self-motivation displayed by the participants showing the most significant weight loss could offer a possible explanation for this outcome [40], and this suggested explanation has been supported in a further study [61]. For countries such as the UK with dedicated military physical training instructors, additional investigations are required to understand the positive or negative influence of fitness instructors.

\section{Behavioural Attributes and Skills}

One behavioural attribute was identified from the 4 studies; Grotto et al. [38] concluded that smoking status (non-smoker) was associated with lower BMI, which is a generally accepted relationship [17]. The military is an institution with an habitual alcohol intake [57], and long-term alcohol intake has been observed to increase BMI [62]. This is an area worthy of investigation within the military.

\section{Social and Cultural Factors}

Bray et al. [20] concluded that Navy personnel, as opposed to individuals serving in the army, airforce and marine corps, displayed a higher prevalence of obesity. One paper has suggested that snacking and a lack of fresh food, which may be specific to ship-bound personnel, may offer an explanation for this finding [34]. Social support was not reported to be a significant factor for weight and fat loss [40]; however, this conclusion is not generally supported [63]. One study [64] offered that those individuals with less social ties were more likely to be obese. Due to the social support network modifications linked to the regular location changes associated with military service, the perceived level of individual social support/isolation should be assessed.

\section{Physical Environmental Factors}

Reduced access to fitness facilities was offered as a correlate of obesity [39] while the restriction was not clarified as actual or perceived. Similar findings have been suggested in the area of PA correlates [37]. Within most military units, fitness facilities are freely available; however, within the operational envi- 
ronment access to fitness facilities could be markedly reduced. Thus the actual and perceived availability of suitable facilities warrants further investigation. Sigrist et al. [39] concluded that the lack of healthy food choices and mixed media 'nutrition'-based messages could influence the prevalence of obesity. Within work-site interventions, pricing has been observed to increase the consumption of healthy snacks [65]. Alternatively, increasing the availability of low-cost convenience foods may contribute to obesity [66]. The issue of food availability and price is, however, a multi-level issue for the military due to the centralised feeding associated with single personnel and the influence of the marital home, and should be further instigated within the environmental constraints.

\section{PA Characteristics}

Grotto et al. [38] concluded that high levels of PA ( $\geq 4$ aerobic sessions/week) were negatively associated with an increase in BMI and that low levels of PA $(<1$ aerobic session/week) were positively associated with overweight in females. Bray et al. [20] postulated that an increase in the prevalence of obesity in military personnel from 1995 to 2002 measured by BMI was associated with an increase in strenuous exercise across the same time period. However, definition of weight status by the use of BMI in isolation could be misleading in a military population as the BMI may simply reflect greater muscle mass [4]. In a review of the variables independently associated with obesity in the European Union, Martinez et al. [17] concluded that low participation in leisure-time PA was associated with higher levels of obesity. Further clarity is required as to the association between PA and obesity. However, to fully appreciate the multiple factors associated with PA, allied to the impact of increasing sedentary behaviours, a wider ranging epidemiological investigation may be required [17].

\section{Conclusions and Recommendations}

This review has highlighted the lack of information available as to the probable correlates of obesity in military personnel. The information that is available on treatment is reflective of an American population and therefore raises significant issues of generalisability for other military populations. For the treatment of obesity, the reviewed papers suggest that a multicomponent approach to obesity within the military offers the most effective method. Whilst insufficient follow-up prohibits conclusions on the long-term efficacy of interventions, the application of CBT to the intervention process was in the main supportive of significant weight loss. However, if theory is to be applied, measurement of the mediating variables should be undertaken as this will indicate the efficacy of the supporting theoretical framework and the mediating effect of the theoretical constructs $[19,41]$. Although seldom mentioned in the reviewed papers, the institutional nature of the armed services may significantly impact on many aspects of an individual's immediate social and environmental surroundings. It follows, therefore, that interventions will need to account for the individual behaviour and the environment in which they interact with. Ecological models [67] may offer a theoretical process that can fully reflect the physical, economic, sociocultural, environmental and policy influences of obesity [68]. Significantly, all of the correlate studies included in the review were of a cross-sectional nature; therefore, causal relationships cannot be implied. Furthermore, in each instance the evidence was based on a single paper and was focussed on a US or Israeli sample, presenting significant generalisability issues for other military populations. It is recommended that future correlate studies on the military should attempt to reflect the multi-factorial nature of obesity [45], the interaction with civilian society, and the immediate institutional environment.

\section{Acknowledgement}

Supported by UK MoD Grant.

\section{Disclosure Statement}

The authors declared no conflict of interest.

\section{References}

$\checkmark 1$ Ezzati M, Lopez AD, Rodgers A, Vander Hoorn S, Murray CL: Selected major risk factors and global and regional burden of disease. Lancet 2002; 360:1347-1360.

2 IOM: Weight Management: State of the Science and Opportunity for Military Programs. Washington, DC, National Academic Press, 2003.

3 U S Medical Surveillance Monthly Report: Diagnosis of overweight / obesity, active components, US armed forces 1998 - 2008, US Armed Forces Health Surveillance Centre 2009;16:2-7.

4 McLaughlin R, Wittert G: The obesity epidemic: implications for recruitment and retention of defence force personnel. Obes Rev 2009;10:693-699.
5 Poston WS, Haddock CK, Peterson AL, Vander Weg MW, Klesges RC, Pinkston MM, DeBon M: Comparison of weight status among two cohorts of US air force recruits. Prev Med 2005;40:602-609.

6 Dall TM, Zhang Y, Chen YJ, Askarinam Wagner RC, Hogan PF, Fagan NK, Olaiya ST, Tornberg DN: Costs associated with being overweight and with obesity, high alcohol consumption, and tobacco use within the military health system's Tricare prime-enrolled population Am J Health Promot 2008;22:120-139.

7 Bradham DD, South BR, Saunders HJ, Heuser MD, Pane KW, Dennis KE: Obesity-related hospitalization costs to the U.S. Navy, 1993 to 1998. Mil Med 2001;166:1-10.
8 Kyröläinen H, Häkkinen K, Kautiainen H, Santtila M, Pihlainen K, Häkkinen A: Physical fitness, BMI and sickness absence in male military personnel. Occup Med (Lond) 2008;58:251-256.

9 Kress AM, Peterson MR, Hartzell MC: Association between obesity and depressive symptoms among U.S. Military active duty service personnel, 2002. J Psychosom Res 2006;60:263-271.

10 Vieweg WV, Julius DA, Benesek J, Satterwhite L, Fernandez A, Feuer SJ, Pandurangi AK: Posttraumatic stress disorder and body mass index in military veterans. Preliminary findings. Prog Neuropsychopharmacol Biol Psychiatry 2006;30:11501154. 
11 Fogelholm M, Malmberg J, Suni J, Santtila M, Kyrolainen $\mathrm{H}$, Mantysaari M: Waist circumference and BMI are independently associated with the variation of cardio-respiratory and neuromuscular fitness in young adult men. Int J Obes 2006;30:962 969.

12 Yokota M, Bathalon GP, Berglund LG: Assessment of male anthropometric trends and the effects on simulated heat stress responses. Eur J Appl Physiol 2008;104:297-302.

13 Loube DI, Loube AA, Mitler MM: Weight loss for obstructive sleep apnoea: the optimal therapy for obese patients. J Am Diet Assoc 1994;94:12911295.

14 Lyons J, Allsopp A, Bilzon J: Influences of body composition upon the relative metabolic and car diovascular demands of load-carriage. Occup Med 2005;55:380-384.

15 Charteris J: Load stress; carrier strain: implications for military and recreational back packing. Ergonomics 2000;1:25-47.

-16 Weinsier RL, Hunter GR, Heini AF, Goran MI, Sell SM: The aetiology of obesity: relative contribution of metabolic factors, diet and physical activity. Am J Med 1998;105:145-150.

17 Martinez JA, Kearney JM, Kafatos A, Paquet S, Martinez-Gonzalez MA: Variables independently associated with self-reported obesity in European Union. Public Health Nutr 1999;2:125-133.

18 Lindquist CH, Bray RM: Trends in overweight and physical activity among U.S. Military personnel, 1995-1998. Prev Med 2001;32:57-65.

19 Sharma M: Behavioural interventions for preventing and treating obesity in adults. Obes Rev 2007;8:441-449.

20 Bray RM, Rae Olmsted KL, Williams J, Sanchez RP, Hartzell M: Progress towards healthy people 2000 objectives among .U.S. Military personnel. Prev Med 2006;42:390-396.

21 NHS Centre for Review and Dissemination: Systematic Reviews. York, York Publishing Services, 2001, p 4.

22 NICE: Methods for the Development of National Institute of Health and Clinical Excellence (NICE) Public Health Guidance, 2nd ed. London, Nationa Institute of Health and Clinical Excellence, 2009.

-23 James LC, Folen R, Earles J: Behavioural telehealth applications in the treatment of obese soldiers; a feasibility project and a report on preliminary findings. Mil Psychol 2001;13:177-186.

24 Davis MK: A comprehensive weight-loss program for soldiers. Mil Med 1996;161:84-88.

25 Earles JE, Kerr B, James LC, Folen RA: Clinical effectiveness of the LE3AN program: a military healthy lifestyle program. J Clin Psychol Med Sett 2007;14:51-57.

26 Simpson M, Earles J, Folen R, Trammel R, James L: The Tripler army medical centre's LE3AN program: a six-month retrospective analysis of program effectiveness for African-American and European-American females. J Natl Med Assoc 2004;96:1332-1336.

27 James LC, Folen RA, Page H, Noce M, Brown J, Britton C: The Tripler LE3AN program: a twoyear follow-up report. Mil Med 1999;164:389-395.

28 Bowles SV, Picano J, Epperly T, Myer S: The life program: a wellness approach to weight loss. Mil Med 2006;171:1089-1094.

29 James LC, Folen RA, Garland FN, Edwards C Noce M, Gohdes D, Williams D, Bowles S, Kellar MA, Supplee E: The Tripler army medical centre LEAN program: a healthy lifestyle model for the treatment of obesity. Mil Med 1997;162:328-332.
30 James LC, Folen RA, Davis MK: A new frontier for clinical health psychologists: our leadership role in the development and management of an inpatient weight management program. Prof Psychol Res Pract 1997b;28:146-152.

31 Trent LK, Stevens LT: Evaluation of the Navy's obesity treatment program. Mil Med 1995;160:326330.

32 Woodruff MA, Linenger JM, Conway TL: An assessment of pre-and post-fitness measures in two remedial conditioning programs. Mil Med 1992; 157:25-30

33 Veverka DV, Anderson J, Auld GW, Coulter GR, Kennedy C, Chapman PL: Use of the stage of change model in improving nutrition and exercise habits in enlisted air force men. Mil Med 2003;168:373-379.

34 Dennis KE, Pane KW, Adams BK, Qi BB: The impact of a shipboard program. Obes Res 1999;7: 60-67.

35 IOM M: Weighing the Options: Criteria for Evaluating Weight-Management Programs. Washington, DC, Institute of Medicine, 1995.

36 Sallis JF, Owen N: Physical Activity and Behavioural Medicine. Thousand Oaks, Sage Publications, 1999.

37 Trost SG, Owen N, Bauman AE, Sallis JF, Brown W: Correlates of adult' participation in physical activity: review and update. Med Sci Sport Exerc 2002;34:1996-2001.

38 Grotto I, Zarka S, Balicer RD, Sherf M, Meyerovitch J: Risk factors for overweight and obesity in young healthy adults during compulsory military service. Isr Med Assoc J 2008;10:607-612.

39 Sigrist LD, Anderson JE, Auld GW: Senior military officers' concerns, motivators and barriers for healthful eating and regular exercise. Mil Med 2005;170:841-845.

40 Croteau KA: Correlates of physical fitness improvement among a Navy remedial exercise sample. Mil Med 2001;166:520-525.

41 Baranowski T, Anderson C, Carmack C: Mediating variable framework in physical activity interventions. How are we doing? How might we do better? Am J Prev Med 1998;15:266-297.

42 Saris WHM, Blair SN, van Baak MA, Eaton SB, Davies PSW, Di Pietro L, Fogelholm M, Rissanen A, Swinburn B, Tremblay A, Westerterp KR, Wyatt H: How much physical activity is enough to prevent unhealthy weight gain? Outcome of the IASO 1st stock conference and consensus statement. Obes Rev 2003;4:101-114.

43 Jakicic JM, Wing R, Butler B, Robertson R: Prescribing exercise in multiple short bouts vs one bout continuous: effects on adherence and cardiorespiratory fitness in overweight women Int $\mathbf{J}$ Obes 1995;19:893-901.

44 Lang A, Froelicher ES: Management of overweight and obesity in adults: behavioural interventions for long-term weight loss and maintenance. Eur J Cardiovasc Nurs 2006;5:102-114.

45 Nammi S, Koka S, Chinnala KM, Boini K: Obesity: an overview on its current perspectives and treatment options. Nutr J 2004;3:3.

46 Hunter CM, Peterson AL, Alvarez LM, Poston WC, Brundige AR, Haddock CK, Van Brunt DL, Foreyt JP: Weight management using the internet a randomized controlled trial. Am J Prev Med 2008;34:119-126.

47 Berkel LA, Carlos-Poston WS, Reeves RS, Foreyt JP: Behavioural interventions for obesity. J Am Diet Assoc 2005;105(suppl 1):S35-43.

48 Blundell JE: What foods do people habitually eat? A dilemma for nutrition, an enigma for psychology. Am J Clin Nutr 2000;71:3-5.
49 Wing R: Behavioural Approaches to the Treatment of Obesity. New York, Marcel Dekker, 1997.

50 Winett RA, Tate DF, Anderson ES, Wojcik JR, Winett SG: Long-term weight gain prevention. A theoretically based internet approach. Prev Med 2005;41:629-641.

51 Jakicic JM, Otto AD: Physical activity considerations for the treatment and prevention of obesity. Am J Clin Nutr 2005;82(1 suppl):226S-229S.

52 Molarius A: The contribution of lifestyle factors to socioeconomic differences in obesity in men and women: a population based study in Sweden. Eur J Epidemiol 2003;18:227-234.

53 Pickett KE, Kelly S, Brunner E, Lobstein T, Wilkinson RG: Wider income gaps, wider waistbands? An ecological study of obesity and income inequality. J Epidemiol Commun Health 2005;59: 670-674.

54 Ulijaszek SJ: Obesity: a disorder of convenience. Obes Rev 2007;8:183-187.

55 Knapik JJ, Bullock SH, Canada S, Toney E, Wells JD, Hoedebecke E, Jones BH: Influence of an injury program on injury and fitness outcomes among soldiers. Inj Prev 2004;10:37-42.

56 Lohmander LS, Englund PM, Dahl LL, Roos EM: The long-term consequence of anterior cruciate ligament and meniscus injuries: osteoarthritis. Am J Sports Med 2007;35:1756-1769.

57 Kilminster S, de sa Roiz D, Bridger RS: Obesity in the Naval Service. Gosport, Institute of Naval Medicine, 2008.

58 Dishman RK, Sallis JF, Orenstein DR: The determinants of physical activity and exercise. Public Health Rep 1985;100:158-171.

59 Hyland R, Stacy R, Adamson A, Moynihan P: Nutrition related health promotion through an afterschool project: the responses of children and their families. Soc Sci Med 2006;62:758-768.

60 WHO: Diet, Nutrition and the Prevention of Chronic Diseases. Report of the Joint WHO / FAO Expert Consultation. Geneva, World Health Organisation, 2003, TRS 916

61 Williams GC, Grow VM, Freedman Z, Ryan RM, Deci EL: Motivational predictors of weight loss and weight loss maintenance. J Person Soc Psychol 1996;17:269-276.

62 Breslow RA, Smothers BA: Drinking patterns and body mass index in never smokers. Am J Epidemiol 2004;161:368-376

63 Cohen DA, Finch BK, Bower A, Saatry N: Collective efficacy and obesity: the potential influence of social factors on health. Soc Sci Med 2005;62:769778.

64 Berkman L, Syme S: Social networks, host resistance and mortality. A nine-year follow-up study of Alameda county residents. Am J Educ 1979:190:186-204.

65 French SA, Jeffery RW, Story M, Hannan P, Snyder PM: A pricing strategy to promote low-fat snack choices through vending machines. Am J Public Health 1997;87:849-851.

66 Cohen DA, Finch BK, Bower A, Sastry N: Collective efficacy and obesity: the potential influence of social factors on health. Soc Sci Med 2006;62:769778

67 Sallis JF, Owen N: Ecological Models of Health Behaviour. San Francisco, Jossey-Bass, 2002.

68 Baranowski T, Cullen KW, Nicklas T, Thompson D, Baranowski J: Are current health behavioural change models helpful in guiding prevention of weight gain efforts? Obes Res 2003;11(suppl):23S$43 \mathrm{~S}$ 